\title{
Extinction coefficients retrieved in deep tropical ice clouds from lidar observations using a CALIPSO-like algorithm compared to in-situ measurements from the cloud integrating nephelometer during CRYSTAL-FACE
}

\author{
V. Noel ${ }^{1}$, D. M. Winker ${ }^{2}$, T. J. Garrett ${ }^{3}$, and M. McGill ${ }^{4}$ \\ ${ }^{1}$ Laboratoire de Météorologie Dynamique, Palaiseau, France \\ ${ }^{2}$ NASA Langley Research Center, VA, USA \\ ${ }^{3}$ Univ. of Utah, UT, USA \\ ${ }^{4}$ NASA Goddard Space Flight Center, Greenbelt, ML, USA
}

Received: 10 February 2006 - Published in Atmos. Chem. Phys. Discuss.: 19 October 2006

Revised: 11 January 2007 - Accepted: 26 February 2007 - Published: 8 March 2007

\begin{abstract}
This paper presents a comparison of lidar ratios and volume extinction coefficients in tropical ice clouds, retrieved using observations from two instruments: the 532nm Cloud Physics Lidar (CPL), and the in-situ Cloud Integrating Nephelometer (CIN) probe. Both instruments were mounted on airborne platforms during the CRYSTAL-FACE campaign and took measurements up to $17 \mathrm{~km}$. Coincident observations from two cases of ice clouds located on top of deep convective systems are compared. First, lidar ratios are retrieved from CPL observations of attenuated backscatter, using a retrieval algorithm for opaque cloud similar to one used in the recently launched CALIPSO mission, and compared to results from the regular CPL algorithm. These lidar ratios are used to retrieve extinction coefficient profiles, which are compared to actual observations from the CIN insitu probe, putting the emphasis on their vertical variability. When observations coincide, retrievals from both instruments are very similar, in the limits of colocation. Differences are generally variations around the average profiles, and general trends on larger spatial scales are well reproduced. The two instruments agree well, with an average difference of less than $11 \%$ on optical depth retrievals. Results suggest the CALIPSO Deep Convection algorithm can be trusted to deliver realistic estimates of the lidar ratio, leading to good retrievals of extinction coefficients.
\end{abstract}

\section{Introduction}

Cirrus clouds are high altitude clouds mostly composed of ice crystals. Since they consistently cover more than $30 \%$

Correspondence to: V. Noel

(vincent.noel@1md.polytechnique.fr) of the earth's surface (Wylie et al., 1994), their influence on the radiation budget cannot be overlooked (Stephens et al., 1990). The radiative influence of a given cirrus cloud depends mostly on the delicate balance between its albedo and greenhouse effects, and, on a local scale, on its microphysical and optical properties. Most noticeably, the quantity of sunlight reflected by a cirrus cloud (and thus its albedo effect) is directly tied to its optical thickness $\tau$, defined as $\tau=\int_{z_{0}}^{z_{1}} \alpha(z) d z$ : the vertical integration of its extinction coefficient $\alpha(z)$ between the cloud boundaries $z_{0}$ and $z_{1}$. The albedo of a cloud is thus directly dependent on its vertical profile of extinction coefficient. A good knowledge of extinction coefficients, and thus optical depth, in cirrus clouds would lead to a better estimation of their general albedo effect.

Due to the high altitude of cirrus clouds, direct in situ measurement of their microphysical properties is a difficult task that cannot be pursued on a systematic basis. Moreover, in the tropics ice clouds are often located on top of deep convective systems (see e.g. Garrett et al., 2004), which means high-altitude observations are a necessity. Because of their large horizontal and vertical extensions, these systems have a large-scale radiative impact on the planet surface and atmosphere (Hartmann et al., 1992), and their creation through fast convection leads to specific microphysic and optical properties (McFarquhar and Heymsfield, 1996; Heymsfield and McFarquhar, 1996). Unfortunately, when conducting satellite studies using passive remote sensing it is often difficult to separate an optically thin ice cloud layer from an underlying convective system, meaning high uncertainties in the retrievals (Chiriaco et al., 2004). This stresses the need for active remote sensing, such as lidar, whose sensitivity to

Published by Copernicus GmbH on behalf of the European Geosciences Union. 
optically thin clouds makes it one of the most appropriate instruments for cirrus study (Platt, 1973) and can give valuable insights into ice cloud microphysics (Noel et al., 2004). Lidar retrievals of extinction coefficients are an effective tool for studying the optical depth of ice clouds out of reach of insitu observations, and are not subject to passive remote sensing limitations, as the variability of extinction coefficients is observed as a function of penetration inside the cloud layer. Moreover, the 532-nm spaceborne lidar in the framework of the CALIPSO mission (Winker et al., 2003) is currently producing retrievals of extinction coefficients and thus optical depths on a global scale, even for tropical ice clouds on top of optically thick convective systems.

In the present study, attenuated backscatter profiles observed in deep tropical ice clouds using the Cloud Physics Lidar (CPL) on 28th and 29th July during the Cirrus Regional Study of Tropical Anvils and Cirrus Layers - Florida Area Cirrus Experiment (CRYSTAL-FACE, Jensen et al., 2004) are used to retrieve lidar ratios, using the CALIPSO "Deep Convection" retrieval algorithm (Winker, 2003). Results are compared to retrievals using the regular CPL algorithm, then with actual in-situ observations from the airborne collocated probe Cloud Integrating Nephelometer (CIN, Garrett et al., 2003). The CRYSTAL-FACE campaign is presented in Sect. 2, along with the instruments used by the present study. The CALIPSO Deep Convection retrieval algorithm is presented and its results compared with results from the CPL algorithm in Sect. 3. Lidar ratio retrievals are then used to retrieve extinction coefficient profiles in Sect. 4, which are compared to in-situ CIN observations. Discussion and conclusion are given in Sect. 5 .

\section{Volume extinction coefficient retrievals during CRYSTAL-FACE}

The CRYSTAL-FACE campaign was held in July 2002 over Florida and the Gulf of Mexico, and aimed to provide the comprehensive measurements needed to better understand the microphysical and radiative properties and formation processes of ice clouds on top of thick convective cloud systems. Five mid- to high-altitude aircraft carried numerous in situ and remote sensing instruments, with simultaneous ground-based observations. Among these, the NASA Cloud Physics Lidar CPL, a three-wavelength $(355 \mathrm{~nm}, 532 \mathrm{~nm}$ and $1064 \mathrm{~nm}$ ) backscatter lidar (McGill et al., 2002), was looking downward from the NASA ER-2 aircraft (King et al., 2003) and provided several days of observations from as high as $20 \mathrm{~km}$, with a vertical resolution of $30 \mathrm{~m}$ and an horizontal resolution of $200 \mathrm{~m}$ at the typical ER-2 flying speed of $200 \mathrm{~m} \cdot \mathrm{s}^{-1}$. The CPL telescope field of view is $100 \mu$ radians, so the footprint on a cloud located less than $10 \mathrm{~km}$ away (the typical distance during CRYSTAL-FACE) would be less than 1 meter wide, i.e. roughly 100 times smaller than CALIPSO's. This configuration allowed unique monitoring of ice clouds located on top of tropical convective systems, which would be impossible from the ground because of the lower layers of thick water clouds blocking the lidar penetration. From the raw backscattered laser light measured by the CPL telescope, properties of cloud and aerosol layers are retrieved, including the altitude of cloud base and cloud top, its optical depth $\tau$, and profiles of depolarization ratio and volume extinction coefficient. The method used for analysis and retrieval of the volume extinction is explained in McGill et al. (2003), and is based on the standard lidar inversion technique (e.g. Spinhirne et al., 1980; Klett, 1981). When possible (i.e. for optically thin clouds), the lidar extinctionto-backscatter ratio $S$ (Sect. 3.1) is retrieved directly from lidar observations (through a transmission-loss technique). When this is not possible (i.e. for optically thick clouds such as convective systems), $S$ is provided below $-13^{\circ} \mathrm{C}$ by a quadratic function of temperature: $S=a T^{2}+b T+c$ with $a=$ $-1.42739 \mathrm{e}-3, b=-2.08944 \mathrm{e}-1$ and $c=1.5339 \mathrm{e}+1$ (Hlavka, private communication, 2005) at a wavelength of $532 \mathrm{~nm}$ (a different quadratic function is used at $1064 \mathrm{~nm}$ ). For temperatures warmer than $-13^{\circ} \mathrm{C}$, the value $S=17.84$ is used. A very similar technique is used when analyzing observations from the spaceborne Geoscience Laser Altimeter System (Zwally et al, 2002).

The CIN probe was mounted on the WB-57 aircraft, which was able to fly through the top of tall convective systems thanks to its high ceiling (up to $18 \mathrm{~km}$ ). The CIN measures extinction coefficients from the scattering of cloud particles of a $635 \mathrm{~nm}$ laser light into sensors, consisting of circular light-diffusing disks and photomultipliers (Gerber et al., 2000). These sensors measure the forward-scattered and backscattered light between $10^{\circ}$ and $175^{\circ}$, from which the volume extinction parameter is inferred based on an estimate of the light forward-scattered by diffraction (Eq. 7 in Gerber et al., 2000). Since diffraction is necessarily one half of scattered energy, the omitted fraction is constrained and is estimated to be $0.57 \pm 0.02$. The lower threshold for extinction measurement by the CIN was $0.0004 \mathrm{~m}-1$ and the estimated uncertainty in the measurements during CRYSTALFACE was $15 \%$ for values of extinction greater than about $0.001 \mathrm{~m}-1$. This error estimate has since been validated using ground and airborne transmissometer probes (Gerber, 2007; Garrett, 2007), which are less sensitive than the CIN but are entirely first principles.

\section{The CALIPSO Deep Convection Algorithm}

\subsection{Lidar ratio retrieval}

For elastic backscatter lidars, volume extinction coefficient profiles $\alpha(z)$ are retrieved from observations of attenuated backscatter profiles $\beta(z)$. In order to do so, a relationship between the backscatter and extinction coefficients must be 
assumed. Often defined as $S=\frac{\alpha}{\beta}$, the lidar ratio, this relation is assumed to stay constant within a cloud layer.

The magnitude of the lidar ratio depends on the microphysical properties of the cloud, but in many cases can be retrieved from attenuated backscatter observations alone. In the routine analysis of CALIPSO observations, different algorithms are used depending on the opacity of the atmospheric layer. For semi-transparent clouds, a transmittance algorithm is used, based on the difference in lidar return signal from clear regions above and below the cloud layer. In the case of fully attenuating layers, such as deep tropical thick convective systems, the transmittance algorithm cannot be applied, as the laser cannot penetrate the full layer and no signal is available beyond the cloud layer. An equation can be derived which relates the cloud-integrated attenuated backscatter signal $\gamma^{\prime}$ to the cloud transmittance $T$ (Platt, 1973; Platt et al., 1999):

$\gamma^{\prime}=\frac{1-T^{2}}{2 S \eta}$

where $\eta$ is a multiple scattering correction factor. In the case of an opaque cloud layer, $T=0$ so that $\gamma^{\prime}=\frac{1}{2 \mathrm{~S}_{\eta}}$. The lidar ratio can thus be retrieved from lidar profiles of attenuated backscatter and an estimate of $\eta$. This is the essence of the algorithm used by CALIPSO to retrieve extinction in the tops of deep convective clouds (Winker, 2003). This algorithm assumes that a mean lidar ratio can be used for an entire lidar profiles, hence it supposes an homogeneous microphysical composition throughout the cloud layer ; since the lidar penetration is limited in optically thick convective systems this is a reasonable assumption.

\subsection{Lidar ratio retrieval on 29th July}

On 29th July, a CRYSTAL-FACE mission focused on a small-scale convective system (McGill et al., 2004) that extended horizontally over $100 \mathrm{~km}$ and up to the tropopause (higher than $14 \mathrm{~km}$ ), meaning the highest several kilometers were composed of ice crystals. CPL observations of attenuated backscatter between 19:18 UTC and 19:42 UTC are shown in Fig. 1 as a function of time and altitude, on a logarithmic color scale. During this timeframe, the ER-2 carrying the CPL flew over the convective system in a straight line, and CPL observations show the top of the system rises from $12 \mathrm{~km}$ at its edges to more than $14 \mathrm{~km}$ in its central area, close to the convective center. The CPL was able to penetrate the cloud layer at least one kilometer before the laser signal was completely attenuated (Fig. 1), but coincident observations from the Cloud Radar System (not shown, Li et al., 2004), also mounted on the ER-2, show this cloud system extended down to the surface. The lidar ratios retrieved during the same timeframe are shown in Fig. 2, using the CPL algorithm (in black) and the CALIPSO Deep Convection algorithm described above (in red). Because of the small

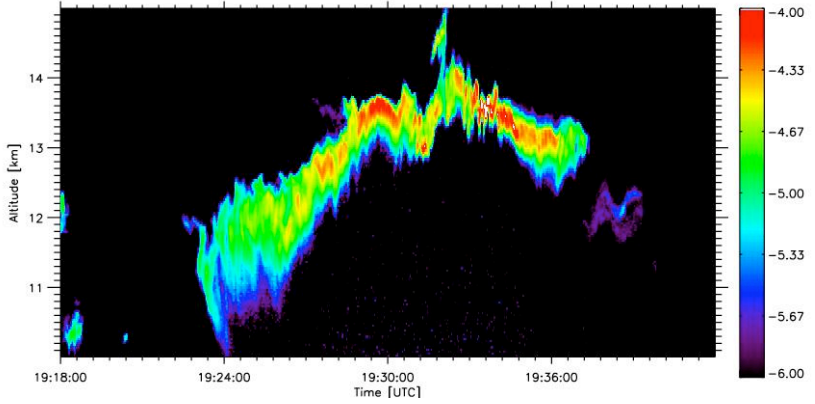

Fig. 1. Attenuated backscatter observed by the CPL as a function of time and altitude from 19:18 UTC to 19:42 UTC on 29th July 2002, using a logarithmic color scale (arbitrary units).

field of view of the CPL instrument and the nearness of the cloud, multiple scattering is insignificant, and the lidar ratio equation (Eq. 1) can be simplified $S=1 / 2 \gamma^{\prime}$. It should be noted that it will only be possible to extrapolate conclusions from the current study to CALIPSO retrievals as far as a valid multiple scattering correction factor is available when using the full Eq. (1) during the CALIPSO analysis. The two sets of values are very similar, most in the 20-40 range, with some outlier points up to 80 . In the opaque portions of the cloud, the agreement is very good; near the cloud edges (not opaque), values derived using the Deep Convection algorithm are too large. In this case, the CALIPSO operational code uses a more appropriate transmittance-based retrieval.

The same comparison was conducted on all cloud layers detected on 29th July, and on similar observations made on 28th July. The average difference and its standard deviation are shown on a logarithmic scale in Fig. 3, as a function of the minimum considered optical depth $\tau_{\min }$. When considering all cloud layers $\left(\tau_{\min }=0\right)$, the average difference goes as high as 100 for 28th July, showing the Deep Convection algorithm leads to unrealistic results in such conditions, as expected. However, as $\tau_{\min }$ increases, the difference quickly decreases below 10 for $\tau_{\min }=0.3$ (29th July) and $\tau_{\min }=1$ (28th July), down to 2 (29th July) and 1 (28th July) for $\tau_{\min }>2$. The standard deviation simultaneously goes through the same decrease, dropping from values greater than 100 to less than 5 . The decrease is especially important for 28th July.

Figure 3 shows that the CALIPSO Deep Convection algorithm is well suited to the study of optically thick cloud layers.

\subsection{Extinction retrieval}

Using the CPL attenuated backscatter observations (Sect. 3.1) and the retrieved lidar ratios (Sect. 3.2), it is possible to retrieve the actual particulate backscatter $\beta(z)$ at the altitude $z$ from the well-known forward solution to the 


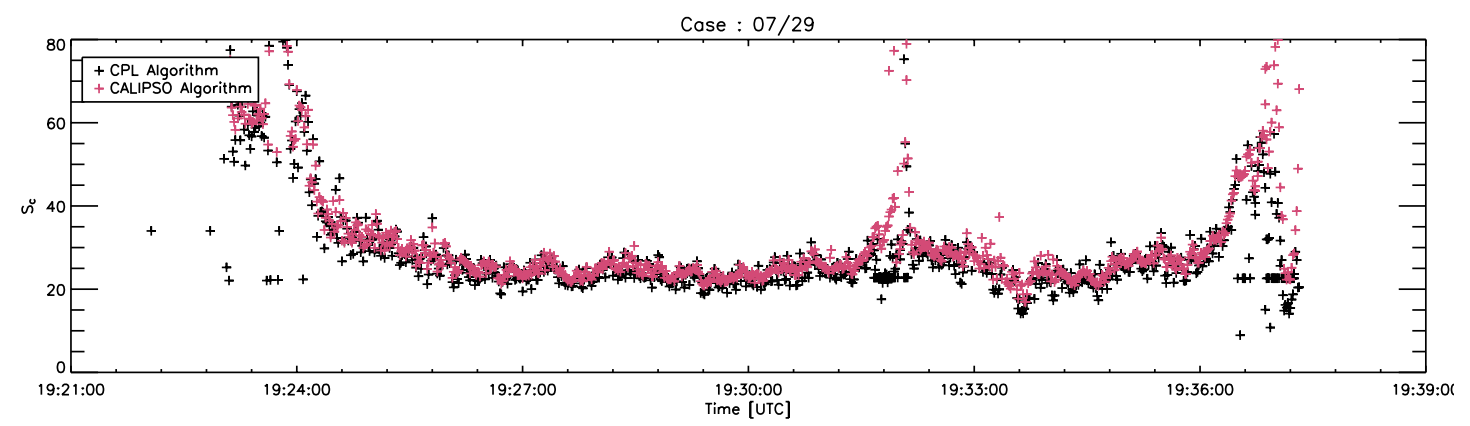

Fig. 2. Lidar ratios $S$ for the same time period shown in Fig. 1, using the CPL retrieval algorithm (black) and the CALIPSO Deep Convection algorithm (red).
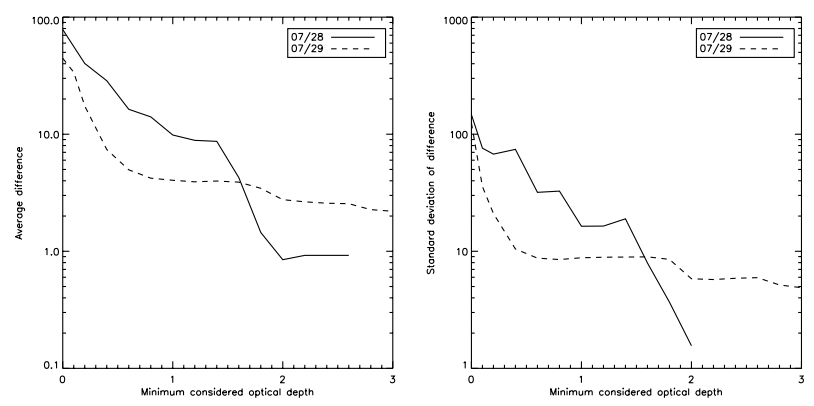

Fig. 3. Difference between lidar ratio $S$ values retrieved using the CALIPSO Deep Convection algorithm and the CPL retrieval algorithm: average (left), standard deviation (right) as a function of the minimum considered optical depth.

lidar equation (Platt et al., 1973):

$\beta(z)=\frac{\beta^{\prime}(z)}{1-2 \eta S \int \beta^{\prime}\left(z^{\prime}\right) d z^{\prime}}$

with $\beta^{\prime}(z)$ the observed attenuated backscatter, and $z_{0}$ the altitude of lidar penetration in the layer (i.e. the cloud top for a nadir-looking lidar like the CPL). As the goal of this study is an operational validation of the CALIPSO Deep Convection algorithm (Sect. 3.1), a simple application of this algorithm will provide a good first approximation for comparison purposes. Once backscatter profiles $\beta(z)$ are retrieved, extinction coefficients $\alpha(z)=\beta(z) \cdot S(z)$ can be easily obtained for any given layer (Sect. 3.1). This technique was applied to CPL observations of attenuated backscatter in ice clouds from 28th and 29th July (Sect. 3.2). Results of these retrievals will be presented and compared to in-situ probe observations in the next section.

\section{Coincident observations of extinction in cirrus clouds}

During CRYSTAL-FACE, cirrus clouds were observed many hours by the CPL (on the ER-2) and the CIN (on the WB-57),
Table 1. Properties of each case of collocated observations from the CPL and CIN during CRYSTAL-FACE.

\begin{tabular}{lll}
\hline & 28th July & 29th July \\
\hline Time of observation & $22: 45-23: 00$ & $20: 01-20: 12$ \\
WB-57 Altitude range & $13.5-16 \mathrm{~km}$ & $12.5-14 \mathrm{~km}$ \\
\hline
\end{tabular}

but most of the time the observations were not simultaneous. This part of the study will focus on the periods of time when the two instruments were functioning simultaneously and their two aircraft were flying in the same area, so that the two instruments were monitoring the same cloud. To evaluate the variability of extinction with altitude, and the correlation between results from both instruments, only cases when the WB-57 was either climbing or descending in the cloud layer were considered. Periods of observation fitting this description for 28th July and 29th are described in Table 1. For each CPL profile, coordinates of the supporting ER-2 aircraft were compared to those of the WB-57 in the timeframe of coincidence, the maximum delay between both aircraft being $10 \mathrm{~min}$.

As seen in Sect. 3.2, the 28th July and 29th cases are typical of the small-scale convective systems that developed frequently in the tropical area monitored during CRYSTALFACE. Volume extinction coefficients retrieved from CPL backscatter observations using the CALIPSO Deep Convection algorithm (Sects. 3.1 and 3.3) are shown in Fig. 4 (28th July) and Fig. 5 (29th July ), with the WB-57 altitude at coincident points plotted over in red symbols. On 28th July , the lidar penetration depth is very variable on time scales of less than a minute: most profiles are fully attenuated before the signal reaches $13 \mathrm{~km}$; however some isolated profiles show deeper penetration and reach $13 \mathrm{~km}$ (e.g. around 22:57 UTC). This seems due to rapid small-scale variations in the spatial distribution of cloud water content. The extinction coefficient is generally in the $10^{-3}$ to $3.10^{-3} \mathrm{~m}^{-1}$ range (green on 


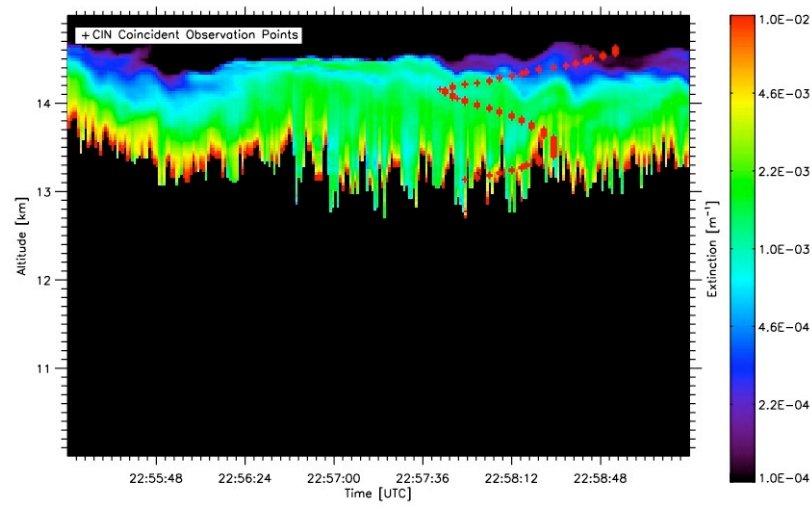

Fig. 4. Extinction $\left(\mathrm{m}^{-1}\right)$ retrieved from CPL backscatter observations and lidar ratio from the CALIPSO algorithm, between 22:55 UTC and 23:00 UTC on 28th July 2002, using a logarithmic color scale. The path of the WB-57, carrying the CIN probe, is plotted in red.

the color scale). The studied timeframe on 29th July (Fig. 5) shows a stable lidar penetration depth, $1 \mathrm{~km}$ on average, but is less homogeneous, with wider variations in retrieved extinction values (from $5 \times 10^{-4}$ to $10^{-2} \mathrm{~m}^{-1}$ ). Integrating these extinction profiles gives a highly variable time series of optical depths (not shown), with values typically ranging between 1 and 4 . As the optical depth approaches these higher values, the retrievals become unreliable for two reasons: 1) it is well known that the forward solution becomes unstable at high optical depths and can become divergent (Platt et al., 1987), and 2) the backscatter return signal becomes very weak and noise excursions influence the retrieved values. Thus extinction coefficients at low altitudes, such as the very high extinctions at the largest penetration depths (red on the color scale in Figs. 4 and 5) should be treated with caution.

For each CPL profile, extinction coefficients were extracted from the CIN data at the point of closest WB-57 and ER-2 coincidence. On 28th July, the WB-57 went from $13 \mathrm{~km}$ at 22:45 UTC up to $16 \mathrm{~km}$ around 23:00 UTC (Fig. 4), a cloud was observed between 22:45 UTC and 22:50 UTC; the ER-2 flew over the same area between 22:55 UTC and 23:00 UTC. To sample the maximum of cloud data, the WB57 was often spiraling inside cloud systems, which is why these points are not in chronological order. The extinction observed by the CIN during this period is shown as symbols in Fig. 6 as a function of altitude, with horizontal bars showing the uncertainty. The average extinction profile retrieved from CPL observations during the same timeframe is shown in full line, the shaded area showing the standard deviation around the average. The agreement between both instruments is good between 13.7 and $15 \mathrm{~km}$, with an average difference of $0.166 \times 10^{-2} \mathrm{~m}^{-1}$ between profiles, which implies that the Deep Convection algorithm is choosing appro-

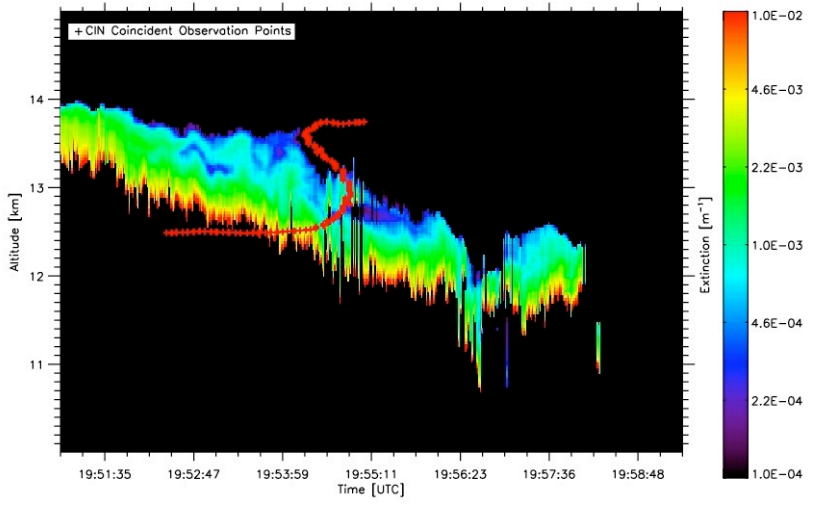

Fig. 5. Same as Fig. 4, for 29th July 2002 between 19:45 UTC and 19:59 UTC.

Table 2. Cloud optical depth $\tau$ obtained from integration of volume coefficient profiles from the CPL and CIN observations.

\begin{tabular}{lll}
\hline & 28th July & 29th July \\
\hline From CPL observations & 1.87 & 5.08 \\
From CIN observations & 1.67 & 4.74 \\
\hline
\end{tabular}

priate values for $S$. Below $13.7 \mathrm{~km}$, colocation between aircraft was not sufficient for comparison. The lidar sees large values of extinction (up to $10^{-2} \mathrm{~m}^{-1}$ ) down to $13.0 \mathrm{~km}$ where the signal gets totally attenuated (radar data shows the cloud base was actually much lower). For colocated measurements, the time difference and horizontal distance between aircraft are not correlated with difference in extinction coefficients. Integrating both CPL and CIN profiles of extinction coefficient over the correlated regions ( 13.7 to $15 \mathrm{~km}$ ) leads to respective optical depths $\tau$ of 1.87 and 1.67 (Table 2), i.e. the CPL-derived value is $11 \%$ larger than the CIN-derived value, within the measurement uncertainties of the two instruments. This difference is negligible in radiative terms, given the limited penetration of the CPL. Integrating the CPL extinction profile over the full layer (i.e. 13 to $15 \mathrm{~km}$ ) gives a much higher value of $\tau=4.6$. This is a very high optical depth for a lidar to penetrate, and indicates the variability of the profile below about $13.7 \mathrm{~km}$ may be due to weak signal and the lowest part of the profile is probably unreliable. The CIN detects some low extinction coefficients $\left(\alpha<5 \times 10^{-4} \mathrm{~m}^{-1}\right)$ at the tropopause level $(15.5 \mathrm{~km}$ according to radiosoundings launched at 23:00 UTC from Tampa, $27.70 \mathrm{~N}, 82.40 \mathrm{~W}$ ) that do not appear in the lidar retrievals (Fig. 6); these values are very close to the CIN noise level $\left(4 \times 10^{-4} \mathrm{~m}^{-1}\right)$ and should not be considered as actual particles. On 29th July, the WB-57 went from $12.5 \mathrm{~km}$ at 20:00 UTC up to $14 \mathrm{~km}$ at 20:04 UTC, then down again at 20:12 UTC (red symbols in Fig. 5). CIN observations of extinction, averaged over altitude bins during this period (Fig. 7) are similar to CPL 


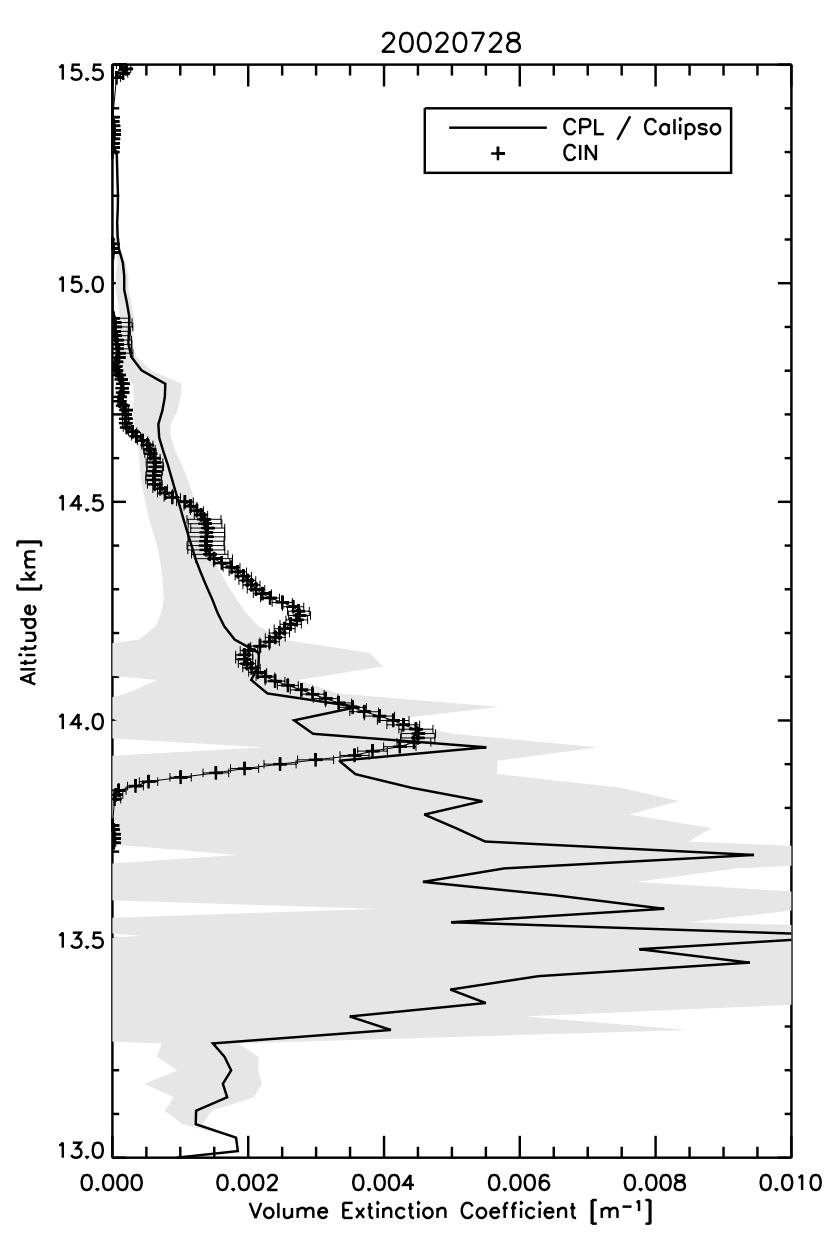

Fig. 6. Profile of extinction coefficients $\left(\mathrm{m}^{-1}\right)$ retrieved from CPL observations using the CALIPSO Deep Convection algorithm (average profile in full line, standard deviation in shaded grey) and from CIN collocated observations (crosses, with instrument uncertainty shown as horizontal bars) for the 28th July case, as a function of altitude $(\mathrm{km})$.

retrievals using the CALIPSO Deep Convection algorithm (the large error bars in CIN extinctions are due to the existence of several data points in a single altitude bin). Consistent with Fig. 5, high extinction coefficients (larger than $5.10^{-3} \mathrm{~m}^{-1}$ ) are observed. Both profiles are in good agreement from cloud top $(14 \mathrm{~km})$ down to $12.5 \mathrm{~km}$, where the colocation between aircraft is too low. The simultaneous sudden break in lidar observations at $12.5 \mathrm{~km}$ is due to total signal attenuation, as radar observations show a lower cloud base. As in the 28th July case, CPL retrievals are highly variable at low altitudes (e.g. below $13 \mathrm{~km}$ ), due to weak signal and the limited stability of the inversion algorithm. Integration of extinction profiles leads to very high optical depths (Table 2): 4.74 and 5.08, respectively for the CPL and the CIN. These values are consistent with the full-profile optical depth for 28th July (4.6). The slightly lower optical depth from CPL extinctions is consistent with total lidar signal attenuation.

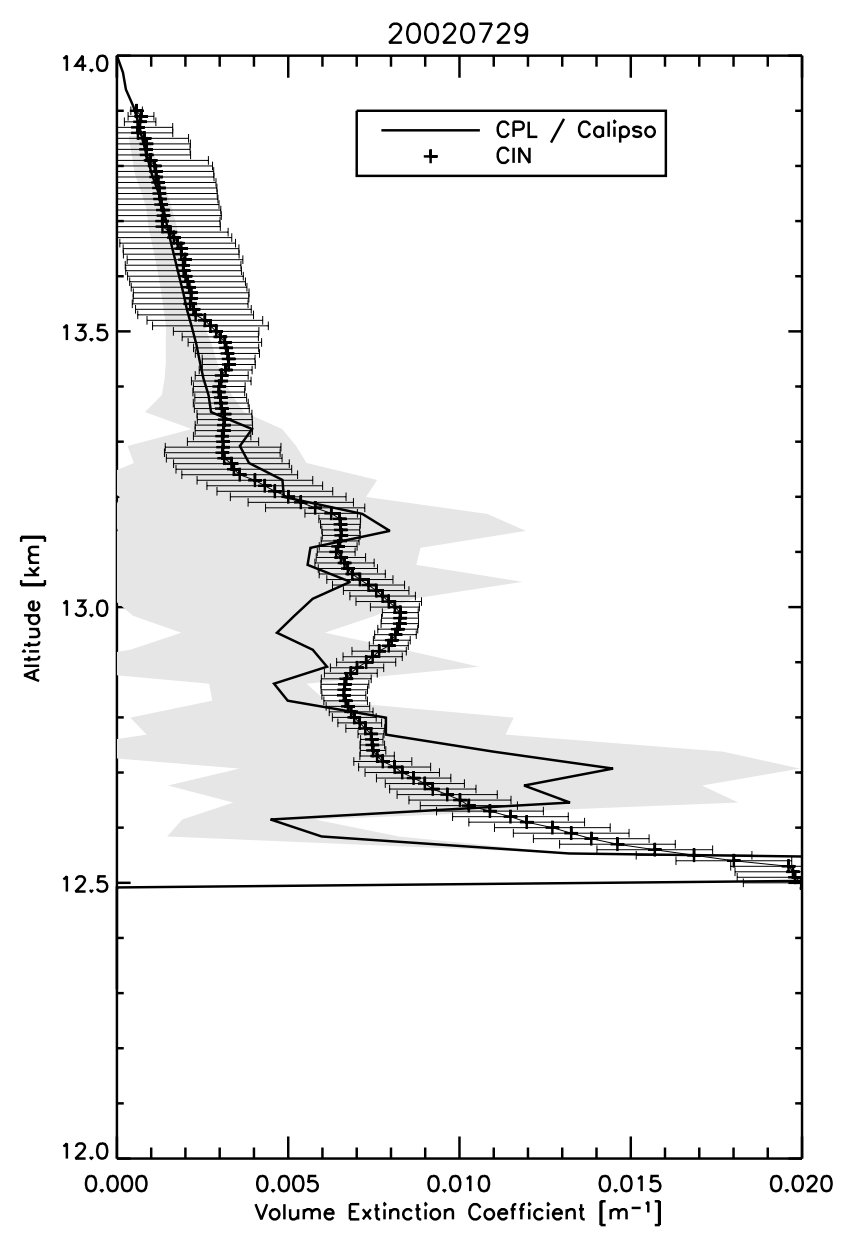

Fig. 7. Same as Fig. 6, for the 29th July case.

\section{Discussion and conclusion}

This study presents a comparison between volume extinction coefficients observed from a CIN in-situ probe and retrievals from lidar backscattering profiles (Sect. 2). Three coincident observation periods are compared, highlighting the variability with altitude (Sect. 4). Results show a very good agreement between both instruments, for extinction coefficients sometimes as low as $10^{-3} \mathrm{~m}^{-1}$ (Fig. 2). This implies the CALIPSO Deep Convection algorithm is doing a good job at selecting lidar ratios for opaque clouds. However, this conclusion was reached using using CPL observations where multiple scattering effects are negligible. Since the footprint of actual CALIPSO observations will be roughly 100 times wider than with CPL, multiple scattering effects will have to be accounted for using an appropriate multiple scattering correction factor (Eq. 1). Retrieval of this parameter depends on additional algorithms and observations and hence is outside the scope of the validation of the Deep Convection algorithm itself.

Overall the extinction coefficient profiles retrieved from CPL observations show higher small-scale variability (in the 
$100 \mathrm{~m}$ range) than the CIN observations, mostly due to the fact that CIN observations were averaged over $11 \mathrm{~s}$ periods in order to increase the signal-to-noise ratio. The CPL variability can be explained by the unstable nature of the extinction retrieval algorithm (Eq. 2) at high optical depths, which creates large fluctuations in backscattering coefficient from one profile to the next - small-scale variations in CPL retrievals should therefore be treated with caution, as they may not be physical. Overall, CIN observations are often contained within the standard deviation of CPL retrievals. As variations on larger scales are well reproduced, the retrieved optical depth is only slightly affected (6 and $11 \%$ difference between the two instruments when considering intersecting observations). In the second case (29th July), the extinction coefficients retrieved from the lidar were slightly lower than those observed in-situ by the CIN. This can be explained by the lidar signal being fully attenuated by the optically thick layer of the convective systems, and thus unable to penetrate the whole cloud layer measured by the CIN. Overall, the lidar performs reasonably well in such extreme conditions (i.e. very thick convective system), and as it was shown previously those differences are only significant on small spatial scales and are only a secondary influence on larger scale trends and integrated results.

Differences in extinction coefficients still exist, though, and might be due to instrumental and algorithmic limitations in both retrieval schemes or spatial and temporal mismatch. For instance, the lidar ratio is assumed to stay constant in all cloud profiles (Sect. 3.1), which is unrealistic if large changes in microphysical properties happen on a single profile basis. A study of ice crystal shape classification from depolarization ratios suggests only limited change in microphysics with altitude above $12 \mathrm{~km}$ in convective cases observed on 28 and 29 July during CRYSTAL-FACE (Noel et al., 2004b), however small-scale variations are still possible. Regarding the CIN, as with many other probes, it has been argued that ice crystals can shatter when impacted by the aircraft or the probe itself, leading to an artificial increase in small particles concentration. Recent comparisons between collocated in-situ probes during CRYSTAL-FACE (Heymsfield et al., 2006) suggest that due to this phenomenon, observations from the CIN might overestimate the extinction coefficient, potentially by as much as a factor of 2 . Gerber (2007) and Garrett (2007) have rebutted this work, arguing that the inferred errors were the result of faulty or inappropriate comparisons. Nonetheless, additional work might therefore be required to determine if the good agreement found between results from both instruments in the present study is the byproduct of distinct observational and analysis biases in each instrument, which would compensate for each other and coincidentally lead to similar results. On the other hand, the fact that results from both instruments, using very different techniques, show a good agreement strengthens the confidence in extinction coefficients retrieved from both instruments. Moreover, even in the case of a quantitative bias, the fact that the variations of extinction coefficient are similar with altitude in same-day profiles from each instrument still suggests the vertical variability of lidar retrievals can be trusted. In any case, retrievals from both instruments are consistent for low values of extinction (below $10^{-3} \mathrm{~m}^{-1}$ ) that would still remain small after a numerical correction. The results are especially important since retrievals from the spaceborne CALIPSO mission (Winker et al., 2003) will soon be available, leading to an extensive mapping of ice cloud optical and microphysical properties.

Acknowledgements. This research was supported in part by the NASA Langley Research Center under contract NAS1-02058. The Cloud Physics Lidar is sponsored by NASA's Radiation Sciences Program and by NASA's Earth Observing System (EOS) office.

Edited by: W. E. Asher

\section{References}

Chiriaco, M., Chepfer, H., Noel, V., Delaval, A., Haeffelin, M., Dubuisson, P., and Yang, P.: Improving Retrievals of Cirrus Cloud Particle Size Coupling Lidar and Three-channel Radiometric techniques, Monthly Weather Review, 132, 1684-1700, 2004.

Chiriaco M., Chepfer, H., Noel, V., Delaval, A., Haeffelin, M., Dubuisson, P. and Yang, P.: Improving Retrievals of Cirrus Cloud Particle Size Coupling Lidar and Three-channel Radiometric techniques, Monthly Weather Review, 132, 1684-1700, 2004.

Garrett T. J., Gerber, H., Baumgardner, D. G., Twohy, C. H., and Weinstock, E. M.: Small, highly reflective ice crystals in low-latitude cirrus, Geophys. Res. Lett., 30, doi:10.1029/2003GL018153, 2003.

Garrett T. J., Heymsfield, A. J., McGill, M. J., Ridley, B. A., Baumgardner, D. G., Bui, T. P., and Webster, C. R.: Convective generation of cirrus near the tropopause J. Geophys. Rev., 109, D21203, 2004.

Garrett T. J.: Comment on "Effective radius of ice cloud particle populations derived from aircraft probes" by Heymsfield et al. (2006), J. Atmos. Ocean. Tech., accepted, 2007.

Gerber, H., Takano, Y., Garrett, T. J., and Hobbs, P. V.: Nephelometer measurements of the Asymmetry parameter, Volume extinction coefficient and Backscatter ratio in Artic clouds, J. Atmos. Sci., 57, 3021-3034, 2000.

Gerber, H.: Comment on "Effective radius of ice cloud particle populations derived from aircraft probes" by Heymsfield et al (2006), J. Atmos. Ocean. Tech., accepted, 2007.

Hartmann, D. L., Ockert-Bell, M. E., and Michelsen, M. L.: The effect of cloud type on earth's energy balance : Global analysis, J. of Climate, 5 , 1281-1304, 1992.

Heymsfield, A. J. and McFarquhar, G. M.: On the high albedos of anvil cirrus in the tropical pacific warm pool: microphysical interpretations from CEPEX and from Kwajalein, Marshall Islands, J. Atmos. Sci., 53, 2401-2423, 1996.

Heymsfield A. J., C. Schmitt, A. Bansemer, G.-J. Van Zadelhoff, M. J. McGill, C. Twohy, D. Baumgardner, 2006: Effective Radius of 
Ice Cloud Particle Populations Derived from Aircraft Probes. J. Atmos. Ocean. Technol., 23, 361-380.

Jensen E. J., Starr, D., and Toon, O. B.: Mission investigates tropical cirrus clouds. EOS, 85, 45-50, 2004.

King, M. D., Platnick, S., Moeller, C. C., Revercomb, H. E., and Chu, D. A.: Remote sensing of smoke, land, and clouds from the NASA ER-2 during SAFARI 2000, J. Geophys. Res., 108(D13), 8502, doi:10.1029/2002JD003207, 2003.

Klett J. D.: Stable analytical inversion solution for processing lidar returns, Applied Optics, 20, 211-220, 1981.

Li L., Heymsfield, G. M., Racette, P. E., Tian, L., and Zenker, E.: A $94-\mathrm{GHz}$ cloud radar system on a NASA high-altitude ER-2 aircraft, J. Atmos. Oceanic. Technol., 21(9), 1378-1388, 2004.

McFarquhar, G. M. and Heymsfield, A. J.: Microphysical characteristics of three cirrus anvils sampled during the Central Equatorial Pacific Experiment (CEPEX), J. Atmos. Sci, 52, 2401-2423, 1996.

McGill M. J., Hlavka, D. L., Hart, W. D., Spinhirne, J. D., Scott, V. S. and Schmid, B.: The Cloud Physics Lidar: Instrument description and initial measurement results. Applied Optics, 41, 37253734, 2002.

McGill M. J., Hlavka, D.L. , Hart, W. D., Welton, E. J., and Campbell, J. R.: Airborne lidar measurements of aerosol optical properties during SAFARI 2000. J. Geophys. Res., 108, 8493, 2003.

McGill, M. J., Li, L., Hart, W. D., Heymsfield, G. M., Hlavka, D. L., Racette, P. E., Tian, L., Vaughan, M. A., and Winker, D. M.: Combined lidar-radar remote sensing: Initial results from CRYSTAL-FACE, J. Geophys. Res., 109, D07203, 2004.

Noel V. and Chepfer, H.: Study of ice crystal orientation in cirrus clouds based on satellite polarized radiance measurements, J. Atmos. Sci., 61, 2073-2081, 2004.

Noel, V., Winker, D. M., McGill, M., and Lawson, P.: Classification of particle shapes from lidar depolarization ratio in convective ice clouds compared to in situ observations during CRYSTALFACE, J. Geophys. Rev., 109, D24213, 2004.
Platt, C. M. R.: Lidar and Radiometric observations of cirrus clouds, J. Atmos. Sci., 30, 1191-1204, 1973.

Platt C. M. R., Scott, J. C. and Dilley, A. C.: Remote sensing of high clouds. Part VI: Optical properties of midlatitude and tropical cirrus, J. Atmos. Sci., 44, 4, 729-747, 1987.

Platt C. M. R., Winker, D. M., Vaughan, M. A., and Miller, S. D.: Backscatter-to-extinction in the Top Layers of Tropical Mesoscale Convective Systems and in Isolated Cirrus from LITE observations. J. Appl. Met., 38, 1330-1345, 1999.

Spinhirne J. D., Reagan, J. A. and Herman, B. M.: Vertical Distribution of Aerosol Extinction Cross-Section and Inference of Aerosol Imaginary Index in the Troposphere by Lidar Technique. J. App. Met., 19, 4, 426-438, 1980.

Stephens, G. L., Tsay, S.-C., Stackhouse, P. W. and Flatau, P. J.: The relevance of the microphysical and radiative properties of cirrus clouds to climate and climate feedback J. Atmos. Sci., 47, 1742-1753, 1990.

Winker, D. M., Pelon, J., and McCormick, M. P.: The CALIPSO mission: Spaceborne lidar for observation of aerosols and clouds, Proc. SPIE, 4893, 1-11, 2003.

Winker D. M.: Accounting for Multiple Scattering in Retrievals from Space Lidar, Proc. SPIE 5059, 128-139, 2003.

Wylie, D. P., Menzel, W. P., Woolf, H. M., and Strabala, K. L.: Four Years of Global Cirrus clouds statistics using HIRS, J. Climate 7, 315-335, 1994.

Zwally, H. J., Schutz, B., Abdalati, W., Abshire, J., Bentley, C., Brenner, A., Bufton, J., Dezio, J., Hancock, D., Harding, D., Herring, T., Minster, B., Quinn, K., Palm, S., Spinhirne, J., and Tomas, R.: ICESat's Laser Measurements of Polar Ice, Atmosphere, Ocean, and Land, J. Geodyn., 34, 405-445, 2002. 